\title{
Investigating the Lifetime of Fibre Ropes
}

\author{
Annett Schmieder*, Markus Golder \\ Professorship of Conveying Engineering and Materials Handling, Chemnitz University of Technology, Chemnitz, Germany \\ * Correspondence: annett.schmieder@mb.tu-chemnitz.de
}

Received 25 August 2020; Review accepted 29 October 2020; Available online 7 December 2020

(C) 2020 by A. Schmieder and M. Golder. This is an open access article distributed under the Creative Commons Attribution License (CC-BY 4.O), which permits unrestricted use, distribution, and reproduction in any medium, provided the original work is properly cited.

\begin{abstract}
Steel wire ropes have established as transmission, connection and safety elements in transporters such as cranes and elevators, due to their high breaking strength and operational safety as well as out of many years of experience. However, steel wire ropes have disadvantages such as high dead weight, high bending stiffness and sensitivity to corrosion. Increasing requirements on the energy-efficient and resource-saving operation of technical systems demand new materials, technologies and processes. As a result, textile machine elements like HM-HT fibre ropes (high modulus, high tenacity) come into focus of considerations. The aim of the research is to expand the level of knowledge with regard to the state of wear and aging. Another aim is to find out the influencing factors on the lifetime, discard criteria of high-strength fibre ropes and to derive methods for lifetime detection.
\end{abstract}

KEYWORDS HM-HT fibre rope, discard criteria, lifetime, transporters, textile machine elements

\section{Introduction}

Due to their favourable breaking force-mass ratio HM-HT fibre ropes are an alternative to steel wire ropes, see Figure 1. Other advantages of using HM-HT fibre ropes compared to steel wire ropes with comparable breaking strength are:

- increase in lifting masses and lengths,

- reduction in the required drive power,

- reduction in bending stiffness,

- good chemical and corrosion resistance and

- good handling during replacement of the suspension element.

With growing innovations, new causes of damage go hand in hand, because there are not enough empirical values and long-term studies of textile machine elements. Accordingly, it is necessary to define discard criteria for HM-HT fibre ropes running over sheaves.

According to DIN EN 12927-6, discard criteria for ropes are defined by the "degree of deterioration at which the rope or the rope end fastening is declared unsuitable for further use“ [1-7]. Knowledge and calculations of rope lifetime are important for the safe operation 




Figure 1: Example of a possible application (crane in New Zealand)

of rope drives. Steel wire ropes are well researched in this regard and have many years of experience. The lifetime of steel wire ropes is assessed according to

- wear on the rope end fixings,

- loosening of the wires,

- fatigue wire breaks,

- corrosion,

- reduction in the metallic cross-section and

- abrasion on the ropes.

In comparison, no discard criteria for running fibre ropes are available in standards like DIN EN ISO 9554 [8] and guidelines like VDI 2500 [9]. DIN EN ISO 9554 [8] defines that every change to a fibre rope in tow rope applications is a discard criterion as soon as the rope can no longer be used. Often this cannot be determined because of the length of the rope or a core-jacket structure. Statements on the degree of damage to the rope are not defined. The lifetime of fibre ropes can only be calculated for selected rope constructions based on tests [10]. In conveyor applications, running fibre ropes (running over sheaves or drums) are subject to tribological stress. This results in aging, wear, fatigue and / or overload signs. Different signs of wear of a running fibre rope are e.g.:

- fatigue of the fibres, such as e. g. fibrillation of the fibres, transverse cracks,

- deforming, twisting the rope, e. g. rope jacket displacement,

- splitting off the fibres,

- breaking of fibres, strands or rope and

- changing the braid length. 


\section{Methods for Testing the Lifetime}

\subsection{Measurement on CBOS Test Machine}

Based on the research studies and knowledge about the signs of wear, different test methods to detect discard criteria of fibre ropes during the CBOS test (cycle bending over sheave) were created. Finally, there are two methods, which include the measurement of an electrical resistance and the detection of visual wear by using a colour sensor. For the tests, different HM-HT fibre ropes were carried out on CBOS machines. The CBOS test machine (a combined test method of visual colour valence measurement and electrical resistance measurement) can be used for 6 - $\mathrm{mm}$-double braid ropes. This provides possibilities for development and evaluation of discard criteria.

Figure 2 shows the test setup of a 5 -zone CBOS test machine with electrical resistance and colour measurement. The machine has five test sheaves (= five zones). In this way, five differently stressed sections of the test rope are created. If a rope section only runs over one of the five sheaves, the rope has $20 \%$ of der bending cycle lifetime. A jacketed 6 -mm-aramidrope (1) is placed on the five sheaves (2) of the CBOS machine.

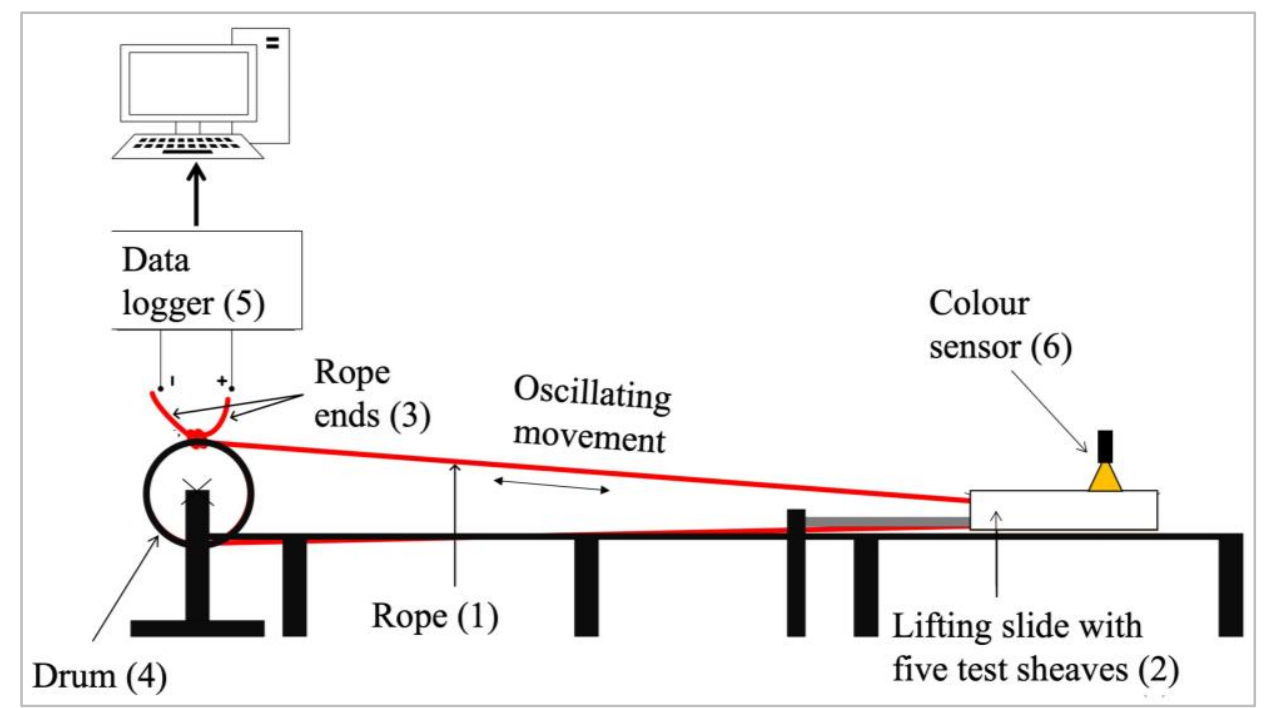

Figure 2: 5-zone CBOS test machine with electrical resistance and colour measurement

\section{Rope and machine parameters}

- Rope breaking force $F_{B}=32 \mathrm{kN}$

- Rope tensile force $S=8 \mathrm{kN}$

- Bending diameter ratio $D / d=25$ ( $D=$ sheave diameter; $d=$ nominal rope diameter $)$

- Bending frequency $f=4.27$ cycles $/ \mathrm{min}$

- Rope construction:

O core: twelve braided aramid strands (Technora ${ }^{\circledR}$ T221, fineness $T t=176 \mathrm{dtex}$ ) with a braid length of $F L=39.0 \mathrm{~mm}$ and uninsulated, electrically conductive copper wires in six of the twelve braided strands,

O jacket: 32 braided strands of white UHMW-PE (e. g. Dyneema ${ }^{\circledR}$ SK75) and black LLCP (e. g. Technora $\left.{ }^{\circledR} \mathrm{T} 221 \mathrm{~b}\right)$ in equal proportions 
The uninsulated, electrically conductive copper wires (core rope) are contacted at the rope ends (3) on a data logger (5). This data logger records the electrical resistance over the entire length of the rope. The measured resistance values per reference length $R$ in $\Omega / \mathrm{m}$ were then assigned to the number of bending cycles $N$. And a colour sensor (6) based on the three-area method is used to detect colour valences and colour dimensions of the rope during the CBOS test.

\subsection{Detection of Discard Criteria by Using Electrical Resistance Measurement}

The aim of this investigation is to measure the change of electrical resistance of an HM-HT fibre rope with uninsulated copper wires during a CBOS test, see Figure 3. This can be used as discard criteria of the rope. As the number of bending cycles increases, the electrically conductive components are also subject to fatigue and wear and will fracture. Uninsulated wires in the rope will always go into another electrical contact and the overall resistance change can be detected.

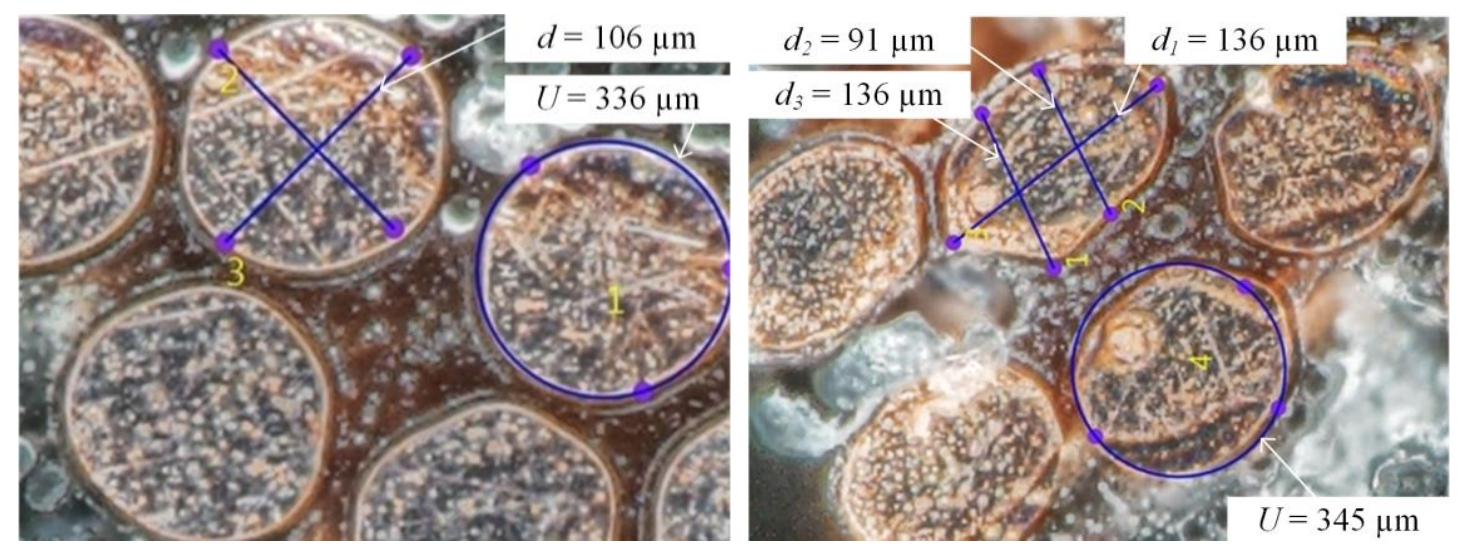

Figure 3: left: Uninsulated copper wires in a new fibre rope (before CBOS test); right: Uninsulated copper wires in a fibre rope after $20 \%$ of lifetime (during CBOS test)

\subsection{Detection of Discard Criteria by Using Colour Sensor Measurement}

HM-HT fibres show different aging and wear phenomena due to alternating bending stress, which become visible by fibrillation, broken strands / fibres and a more voluminous surface, see Figure 4 and Figure 5.



Figure 4: New aramid fibre 


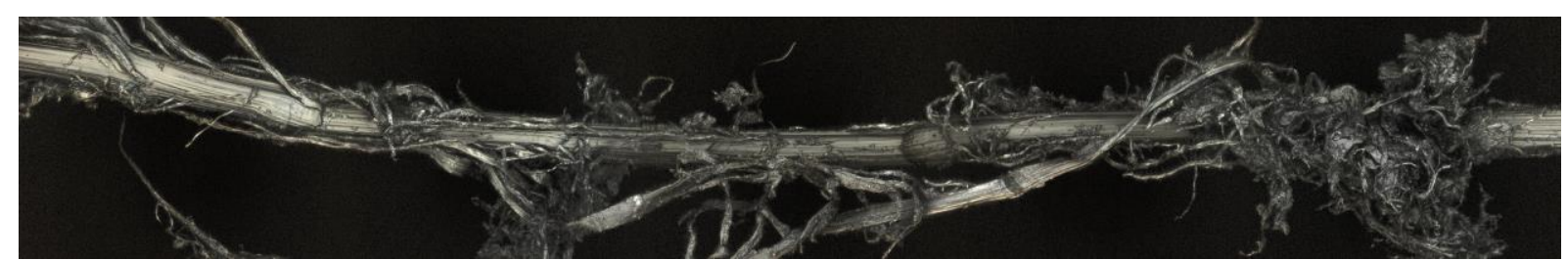

Figure 5: Fibrillation of an aramid fibre



Figure 6: left: New fibre rope; middle: Fibre rope after $20 \%$ bending lifetime; right: Fibre rope after $80 \%$ bending lifetime

However, the degree of damage to a fibre rope subjected to alternating bending cannot be estimated and assessed by the user. For this reason, a test method to detect the discard criteria by using a colour sensor measurement was created. This method to detect discard criteria of a fibre rope based on a wear-related change in the colour dimensions of the rope during the CBOS test, see Figure 6.

\subsection{Measuring Sheave}

With regard to different test methods and on the basis of the knowledge gained, the idea of a split sheave was created. The sheave should serve as a measuring instrument for determining the discard point. Conventional sheaves are made entirely of metal. The developed sheave is a split sheave and has in addition to metallic flanks two insulating intermediate layers. In this way an electric signal of a HM-HT fibre rope with integrated insulated copper strands is possible. The principle of the measurement is based on the stripping of insulation from the copper strands with increasing wear. As a result, uninsulated wires come out from the braided strands and bridge the insulating intermediate layer of the sheave. This creates an electrically measurable signal that can be used as a discard criterion. Figure 7 shows the sheave. The sheave is available for CBOS tests machines. 


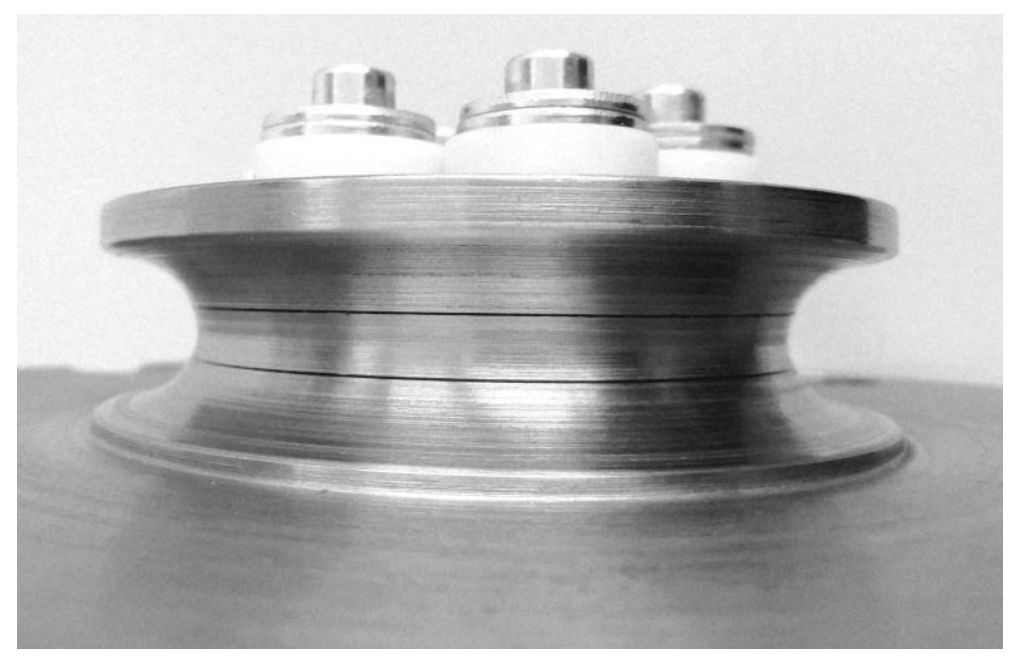

Figure 7: Split sheave with two insulating intermediate layers

\section{Results}

\section{Electrical Resistance Measurement}

With increasing number of bending cycles, the wires inside the HM-HT rope break and go into new contact with each other. The symmetrical arrangement of the copper strands and their helical course in the braid ensure that there are enough contact points in the rope. Figure 8 shows the resistance fluctuations at approx. $20 \%$ and $80 \%$ of the lifetime due to the oscillating movement of the rope over the sheaves during the CBOS test. This can be used as a discard criterion. It can be assumed that broken wires increasingly contact each other as they run in and out in the straight state of the alternating bending. At these points, the lower resistance of the resistance fluctuations can be measured at approx. $20 \%$ and $80 \%$ of the lifetime.

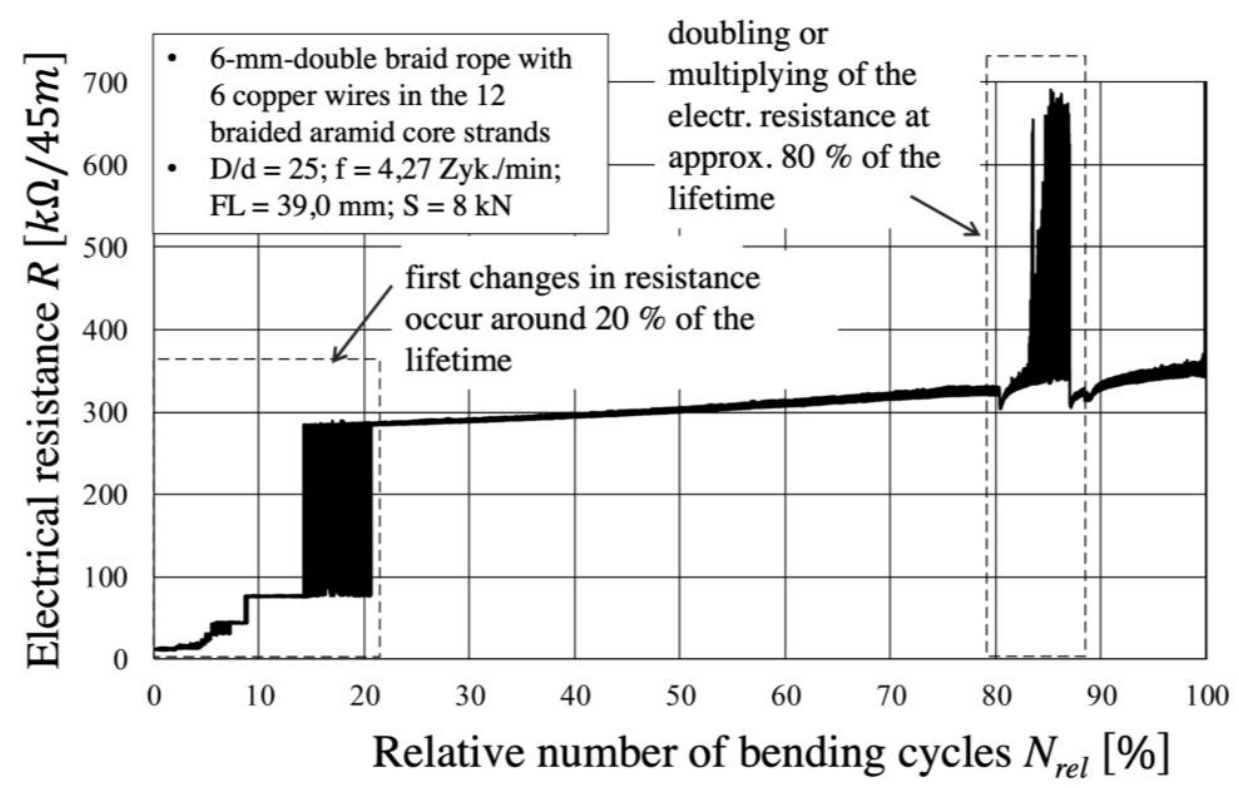

Figure 8: Electrical resistance measurement during CBOS test 


\section{Colour Sensor Measurement}

All examined HM-HT ropes show the first visible signs of wear after $10 \%$ to $20 \%$ of the bending cycle lifetime. This is based on the removal of the fibre finishing and the subsequent abrasive wear behaviour of the HM-HT fibres. Inside the rope, tangential relative movements take place due to fibre-fibre friction. After the removal of the fibre finishing, there is no longer a lubricating film between the fibres. This results in wear of fibres with increasing number of bending cycles. As a result, the abrasive fibrillated HM-HT fibres and change the colour gloss or the colour dimensions of the rope surface.

Furthermore, Table 1 shows both visual and metrological findings of the test rope during the alternating bending test.

Table 1: Visual and metrological findings of a test rope during a CBOS-test

\begin{tabular}{ll}
\hline Signs of wear up to $\mathbf{2 0} \%$ of the rope lifetime & Signs of wear up to $\mathbf{8 0} \%$ of the rope lifetime \\
\hline $\begin{array}{l}\text { The first visual signs of wear can be detected, this is } \\
\text { reflected in an at least 3-fold increase of the change in } \\
\text { resistance. }\end{array}$ & $\begin{array}{l}\text { Broken fibres / strands cause a larger rope diameter to } \\
\text { increase - this is accompanied by an increase in } \\
\text { resistance of at least double. }\end{array}$ \\
$\begin{array}{l}\text { The fibre finishing has been removed from the active } \\
\text { rope surface and can therefore no longer act as a } \\
\text { lubricant. }\end{array}$ & $\begin{array}{l}\text { Up to } 80 \% \text { of the lifetime, the fibres are subject to } \\
\text { increasing fatigue behavior and break, finally the } \\
\text { electrical resistance increases with each strand break. }\end{array}$ \\
\hline
\end{tabular}

\section{Conclusion}

As part of the work at Chemnitz University of Technology, the first discard criteria based on specific visual signs of wear of the fibres and the changed electrical resistance with increasing number of bending cycles was derived. Nevertheless, further tests and combined test methods are indispensable in order to use the previous knowledge with approx. $20 \%$ and $80 \%$ of the fatigue life as discard criteria as a safety criterion.

The load-bearing core should consist of HM-HT fibres such as LLCP or UHMW-PE and have at least one non-insulated electrically conductive component in each braided strand. The rope jacket should consist of white UHMW-PE (e.g. Dyneema ${ }^{\circledR S K 75}$ ) and black LLCP braided strands (e.g. Technora ${ }^{\circledR} \mathrm{T} 221 \mathrm{~b}$ ) in equal proportion in order to be able to determine changes in the colour dimensions during the CBOS test.

\section{References}

[1] Heinze, T.: Zug- und biegewechselbeanspruchte Seilgeflechte aus hochfesten Faserseilen, Dissertation, TU Chemnitz, 2013

[2] Michael, M.: Beitrag zur Treibfähigkeit von hochfesten synthetischen Faserseilen, Dissertation, TU Chemnitz, 2011

[3] Berndt, D.: Inbetriebnahme eines Prüfstandes und Versuche zur Treibfähigkeit von HM-HT Faserseilen im Umgebungsklima eines Erzbergwerkes, Masterarbeit, TU Chemnitz, 2018

[4] Putzke, E.: Untersuchung von Polymermodifikatioren für deren Einsatz in synthetischen Fasern, TU Chemnitz, 2011 
[5] Mammitzsch, J.: Untersuchungen zum Einsatz von ultrahochmolekularen Polyethylenfasern in Seilen für die Fördertechnik, TU Chemnitz, 2015

[6] Hobbs, R. E. / Burgoyne, C. J.: Bending fatigue in high-strength fibre ropes, In: Int J Fatigue 13(No. 2): S.174180, 1991

[7] Hearle, J. W. S. / Lomas, B. / Cooke, W. D.: Atlas of Fibre Fracture and Damage to Textiles, Cambridge, England: CRC Press, 1998

[8] Norm DIN EN ISO 9554: Faserseile - Allgemeine Festlegungen, ICS 59.080.50, Berlin: Beuth Verlag GmbH, 2011

[9] VDI 2500: Faserseile: Beschreibung - Auswahl - Bemessung, Düsseldorf: Verein Deutscher Ingenieure e. V., 1990

[10] Feyrer, K.; Vogel, W.: Hochfestes Faserseil beim Lauf über Seilrollen, 42. Aufl., 1991 